\title{
Effect of Residual Stress on the Corrosion Behavior of Austenitic Stainless Steel
}

\author{
Osamu Takakuwa*, Hitoshi Soyama \\ Department of Nanomechanics, Graduate School of Engineering, Tohoku University, Sendai, Japan \\ Email: ${ }^{*}$ o_takakuwa@mm.mech.tohoku.ac.jp
}

Received 26 December 2014; accepted 9 January 2015; published 15 January 2015

Copyright $(2015$ by authors and Scientific Research Publishing Inc.

This work is licensed under the Creative Commons Attribution International License (CC BY). http://creativecommons.org/licenses/by/4.0/

(c) (i) Open Access

\begin{abstract}
In this paper we demonstrate that the residual stress introduced by several different surface finishes affects the critical current density for passivation and the passive current density in the anodic polarization curve of austenitic stainless steel and that those critical current densities can be reduced by controlling the residual stress by applying a cavitating jet to the backs of specimens. The results show that the current density either increased or decreased depending on the surface finish, and that was decreased by introducing compressive residual stress for all surface finishes.
\end{abstract}

\section{Keywords}

Residual Stress, Corrosion, Passive Film, Plarization, Stainless Seel

\section{Introduction}

The objective of this paper is to demonstrate the effect of residual stress on the corrosion behavior in austenitic stainless steel 316L. Residual stress is introduced into machine components and structures by surface finishing and/or heat treatments, and this affects the fatigue life and resistance to stress corrosion cracking [1] [2]. Several surface finishes such as a polisher and grinder are used for finishing the surface and removing the asperity generated by welding process at surface of components and structures. For improving the reliability of components and structures, mitigating the tensile residual stress is needed. The introduction of compressive residual stress in the surface layer can enhance the fatigue life and resistance to stress corrosion cracking, whereas tensile residual stress does the opposite [3] [4]. For this reason, peening techniques using the impact of shot [5], cavitation bubbles collapsing [6] or pulsed laser [7] have been developed in order to introduce compressive residual stress in practical applications. Since the residual stress at the surface is a significant factor, it is important to understand the effect of this on the corrosion behavior of materials, particularly for components and structures used in cor-

${ }^{*}$ Corresponding author. 
rosive environments. Therefore, in this paper, we show the effect of the residual stress, not on stress corrosion cracking, but on the corrosion behavior. We do this by measuring the anodic polarization curve, and evaluating the critical current density for passivation and the passive current density while controlling the residual stress at the surface.

Improving the resistance of a material to corrosion is necessary to increase its life and reliability in a corrosive environment; consequently, several studies have been conducted on the corrosion behavior of metals. In particular, stainless steel has been developed for use in corrosive environments, and the corrosion resistance and electrochemical behavior have been widely studied [8]-[11]. The corrosion behavior can be evaluated from the polarization curve, which is obtained by measuring the current density as it varies with applied voltage in steel soaked in a corrosive solution. In this paper, the applied voltage was increased from the natural potential which is the equilibrium potential of the cathodic and anodic reactions. The current density required to generate a passivation film, i.e., the critical current density for passivation, and the current density required to maintain the passivation layer, i.e., the passive current density, were used as indices of corrosion behavior by reference to previous studies [10] [11].

In the case of stainless steel, it is well-known that chromium reacts in preference to iron and that the progress of corrosion is suppressed by generating a passivation film. The corrosion behavior is affected by several factors such as the metallic structure, i.e., whether it is austenite, martensite or ferrite. The current density in austenite was increased by generating ferrite and carbide by a heating effect during the welding process [12]. In contrast, it was decreased by laser peening and shot peening with the introduction of compressive residual stress and nanocrystallization in 316L and 304 stainless steels [13]-[15]. It has been reported that the cold rolling ratio, which includes changes in the metallic structure and the residual stress, affects the corrosion behavior in 304 and 316L stainless steels [16]-[18]. Since there is a possibility that the residual stress in the surface layer affects the critical current density and the current density for passivation which are closely related to formation and retention of the passivation layer, it should be investigated. Several surface finishes are used at the end of process such as removing the roughness generated by welding process in the chemical and/or power plant. It affects the surface texture [19] and the sensitivity of stress corrosion cracking. A. Turnbull demonstrated that the surface machining and grinding affected the residual stress at surface layer, and consequently, it affected the stress corrosion cracking behavior [20].

In this paper, in order to demonstrate the effect of residual stress on the corrosion behavior in austenitic stainless steel, specimens made of Japanese Industrial Standards JIS SUS316L were treated by several different surface finishes, and then subjected to a corrosion test using an electrochemical method. The residual stresses in the specimens were controlled by generating curvature in them by exposing the backs of them to a cavitating jet. The effect of residual stress on the current densities related to generating and maintaining a passivation film at the surface was investigated.

\section{Experimental Apparatus and Procedures}

Figure 1 shows a schematic diagram of the apparatus used to measure the anodic polarization curve. This measurement was conducted based on the Japanese Industrial Standards JIS G 0579. The corrosive solution was a 5 percent by mass $\mathrm{H}_{2} \mathrm{SO}_{4}$ solution. The solutions were prepared by adding the requisite amount of ion-exchanged water, with the temperature maintained at 30 degrees Celsius in a temperature-controlled bath. The test electrode was the specimen. The counter electrode and reference electrode were a platinum electrode and a silver-silver chloride $(\mathrm{Ag} / \mathrm{AgCl})$ in saturated $\mathrm{KCl}$ electrode, respectively. Only an area of $24 \mathrm{~mm}$ diameter was exposed to the solution using the plastic holder shown in Figure 2. The standoff distance between the surface and the Luggin probe is $1 \mathrm{~mm}$. Before conducting the corrosion test, the test solution was deaerated by flowing Argon gas through it at greater than $100 \mathrm{ml} / \mathrm{min}$ for more than half an hour, and the surface of the specimen was cathodically treated for 10 min with the potential on the potentiostat at $-0.7 \mathrm{~V}(\mathrm{Ag} / \mathrm{AgCl})$ in the solution. The specimen was then left for $10 \mathrm{~min}$ at its natural potential. Finally, the anodic polarization curve was measured by running the potentiostat from the natural potential to $1.1 \mathrm{~V}(\mathrm{Ag} / \mathrm{AgCl})$ at $20 \mathrm{mV} / \mathrm{min}$ with 5 second intervals.

Each specimen was made of well-tempered 316L austenitic stainless steel. The chemical composition is shown in Table 1. They were square specimens with a thickness of $2.8 \mathrm{~mm}$ and side length of $35 \mathrm{~mm}$ as shown in Figure 3 . The surfaces of the specimens were finished by several different surface finishes as shown in Table 2.

The effect of residual stress on current density was investigated after surface finishing; however, there are 
Table 1. Chemical composition of the 316L austenitic stainless steel.

\begin{tabular}{cccccccccc}
\hline Element & $\mathrm{C}$ & $\mathrm{Si}$ & $\mathrm{Mn}$ & $\mathrm{P}$ & $\mathrm{S}$ & $\mathrm{Ni}$ & $\mathrm{Cr}$ & $\mathrm{Mo}$ \\
\hline Content (wt\%) & 0.014 & 0.630 & 0.970 & 0.030 & 0.004 & 12.030 & 17.450 & 2.050 \\
\hline
\end{tabular}

Table 2. Variation of surface finish.

\begin{tabular}{cc}
\hline Specimen & Surface finish \\
\hline A & Electropolsih \\
B & Emery paper \#800 \\
C & Ceramic rubber polisher \#240 \\
D & Angle grinder A/WA36P \\
\hline
\end{tabular}

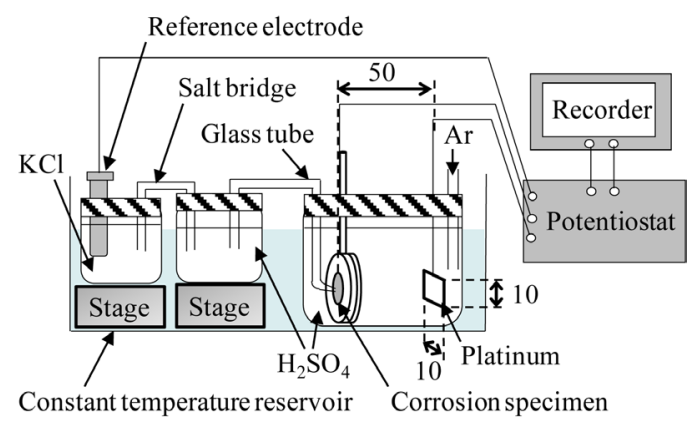

Figure 1. Apparatus for anodic polarization measurement.

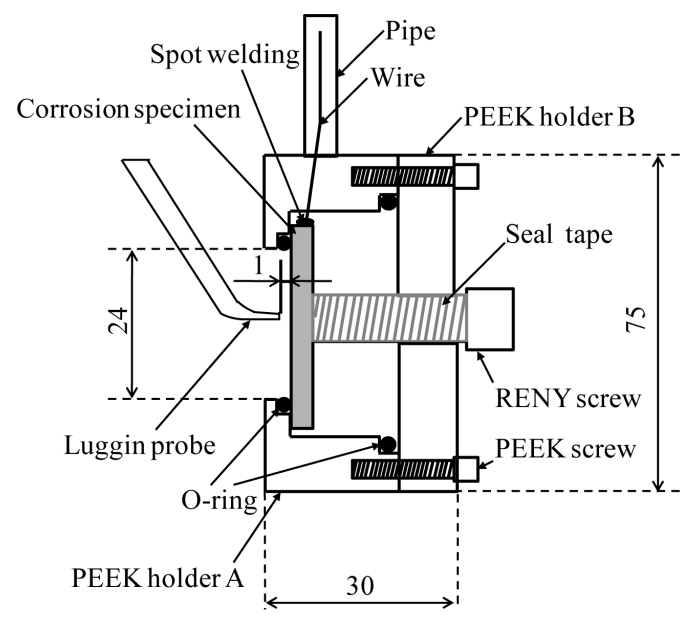

Figure 2. Specimen holder for electrochemical cell.

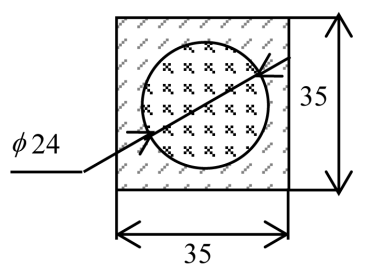

Figure 3. Geometry of the specimen. 
factors other than residual stress that vary with surface finishing that can affect the corrosion behavior. In order to investigate the effect of residual stress without altering the metallic structure of the specimen introduced by the surface finish, the residual stress was controlled by exposing the back of the specimen to a cavitating jet to generate curvature and introduce compressive stress at the front [21]. Figure 4 shows a schematic diagram of the cavitating jet apparatus. A high-speed water jet pressurized by a plunger pump is injected through a nozzle into a water filled tank, generating cavitation around the shear layer of the jet. The cavitating conditions were determined based on previous results [22]. The injection pressure of the cavitating jet and the pressure in the tank were set to $30 \mathrm{MPa}$ and $0.42 \mathrm{MPa}$, respectively. In addition, the nozzle diameter and the standoff distance between the nozzle and the specimen were $2 \mathrm{~mm}$ and $85 \mathrm{~mm}$, respectively. To vary the curvature generated by the cavitating jet, i.e., to vary the compressive residual stress, the specimens were exposed to the jet for various times $(0,10,20,40,80$ seconds), and the variation of the residual stress with curvature was evaluated by the $\sin ^{2} \psi$ method.

The surface residual stress caused by the surface finish, $\sigma_{R}$, was evaluated using an X-ray diffraction method employing an X-ray tube with a $\mathrm{Cr}$ target operated at $30 \mathrm{kV}$ and $8 \mathrm{~mA}$. X-rays from the $\mathrm{K} \beta$ peak were chosen. The angle of the solar slit was 1 degree and the slit width was $4 \mathrm{~mm}$. The diffractive angle $2 \theta$ was varied from 143.5 to 153.5 degrees in steps of 0.2 degree, and the diffractive X-rays were counted for 3 sec. at each step using a scintillation counter at angles of $\psi=0,22.8,33.2,42.2$ and 50.8 degrees. The diffractive plane was the (3 11 ) plane of $\gamma$-Fe. The diffractive angle without strain $2 \theta_{0}$ was 148.5 degrees, and the stress factor was -368.9 $\mathrm{MPa} / \mathrm{deg}$. The diffractive angle was determined by a half value width method, and the residual stress was calculated by a $\sin ^{2} \psi$ method. In addition, in order to investigate the effect of the surface finish on the X-ray profile, it was obtained by employing a Cu target operated $40 \mathrm{kV}$ and $40 \mathrm{~mA}$. The diffractive plane was the (1 111 ) plane of $\gamma$-Fe. After measurements of the residual stress and X-ray profile, anodic polarization measurements were conducted using the above conditions.

\section{Results}

Figure 5 shows the residual stresses at the surface generated by each surface finish. In Figure 5, the residual stresses, $\sigma_{R}$, before surface finishing (electropolish) are $19 \mathrm{MPa}$, and after surface finishing they have several

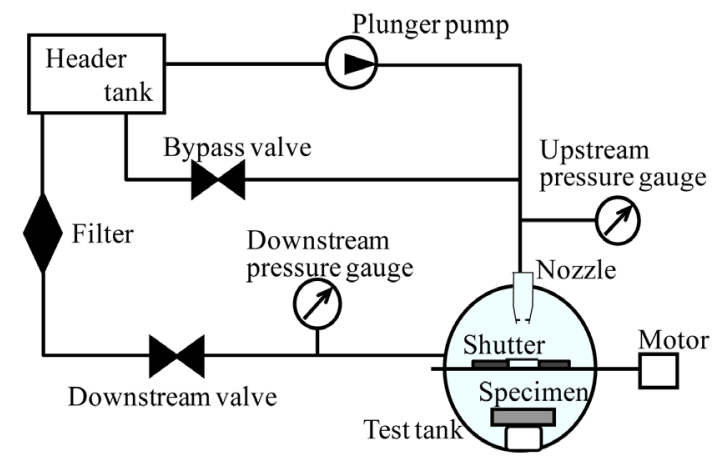

Figure 4. Apparatus for anodic polarization measurement.

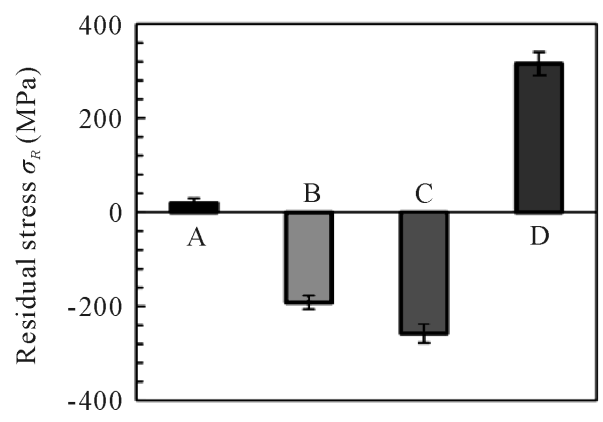

Figure 5. Residual stress introduced by each surface finish. 
various values. In particular in the case of specimen D (Angle grinder), a large tensile residual stress was introduced, with $\sigma_{R}=315 \mathrm{MPa}$. The residual stress for specimens B (Emery paper \#800), C (Rubber polisher \#240) are 192 and $257 \mathrm{MPa}$ in compression, in contrast to specimen D (Angle grinder). The difference in residual stress is due to the different surface finish, and this may generate different corrosion behavior. The following paragraph describes the differences in the anodic polarization curves obtained from the corrosion tests.

Figure 6 shows the current density as a function of electrode potential for each specimen. The current density was obtained by dividing the current by the test area. As shown in Figure 6, the current density varies depending on the surface finish. The surface finish affects the surface texture such as dislocation structure at surface produced by plastic deformation in the process of surface finish, grain size and residual stress at the metal surface. However, it is difficult to pick over the effect of those factors on the corrosion behavior, and the objective of this study is to investigate the effect of residual stress. At the same time, these other effects can be excluded by control of the residual stress only. We varied the residual stress without change of other factors, as described in the following paragraph.

Figure 7 shows the changes in residual stresses, $\Delta \sigma_{R}$, due to the application of a cavitating jet to the backs of the specimens as functions of exposure time, $t$. Despite the small differences, in each case, the residual stress becomes increasingly compressive, with increasing cavitating jet processing time. These increase up to a processing time of $\sim 40 \mathrm{sec}$, and then saturate beyond that. Apart from specimen D (Angle grinder), $\Delta \sigma_{R}$ is about $80 \mathrm{MPa}-200 \mathrm{MPa}$. In the case of specimen D, $\Delta \sigma_{R}$ is almost $300 \mathrm{MPa}$. Figure 8 indicates that this method can be used to control the residual stress and can be applied to exclude factors other than residual stress which affect corrosion behavior.

Figure 8 shows the anodic polarization curves for each surface finish for various exposure times to the cavitating jet. Despite the small difference, the current density in the passive region decreases as a whole with increasing processing time for all specimens as shown in Figure 8. The current densities for each specimen at $t=$

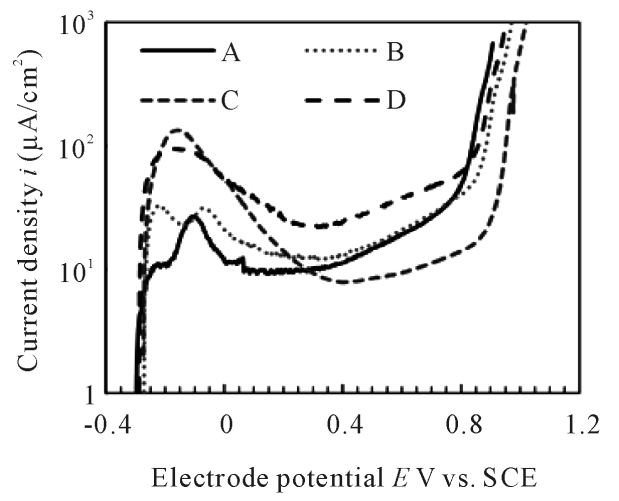

Figure 6. Anodic polarization curves for each surface finish.

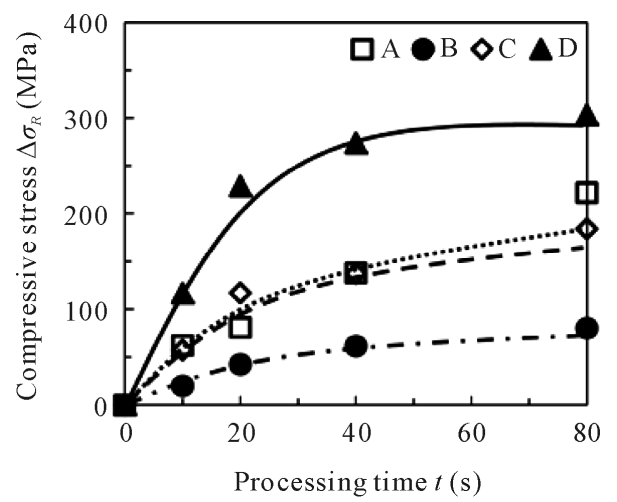

Figure 7. Change in residual stress with processing time of cavitating jet treatment at the back of the specimen. 


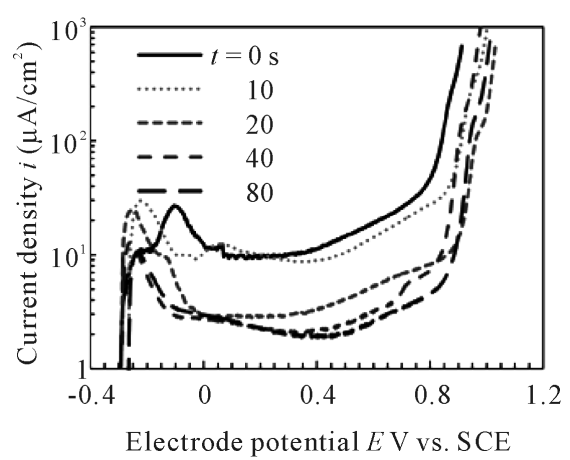

(a)

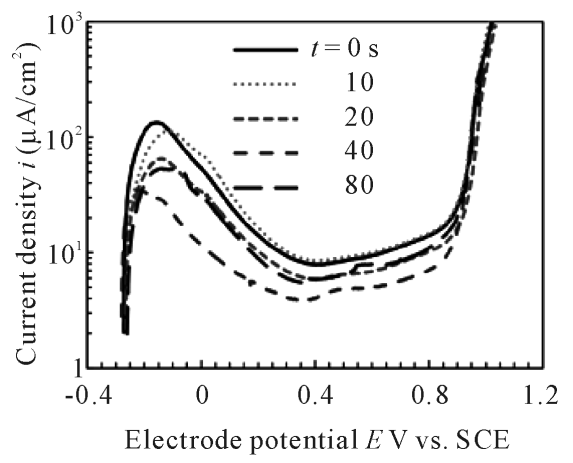

(c)

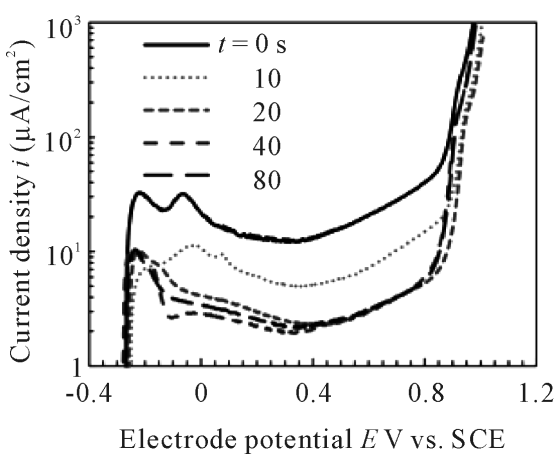

(b)

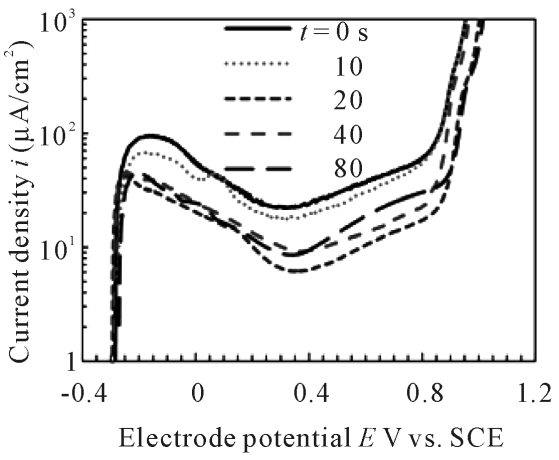

(d)

Figure 8. Change in anodic polarization curve after cavitating jet treatment at the back of the specimen.

10 sec. and 20 sec. decrease rapidly from those at $t=0$, and show the same tendencies as the variations in residual stresses shown in Figure 7. In order to clarify the effect of residual stress on the critical current density for passivation, $i_{c r i t}$, and the passive current density, $i_{\text {pass }}$, Figure 9 and Figure 10 show these as functions of residual stress for each specimen. As shown in Figure 9 and Figure 10, $i_{\text {crit }}$ and $i_{\text {pass }}$ decrease with the introduced compressive stress for all specimens. In the case of the specimen without a surface finish (specimen A; Electropolish), $i_{\text {crit }}$ and $i_{\text {pass }}$ are $27 \mu \mathrm{A} / \mathrm{cm}^{2}$ and $9 \mu \mathrm{A} / \mathrm{cm}^{2}$ at $\sigma_{R}=19 \mathrm{MPa}(t=0 \mathrm{~s})$, and these parameters rapidly decrease with increasing compressive stress. Those parameters were saturated at $11 \mu \mathrm{A} / \mathrm{cm}^{2}$ and $2 \mu \mathrm{A} / \mathrm{cm}^{2}$ at $\sigma_{R}=-202$ $\operatorname{MPa}(t=80 \mathrm{~s})$. In all specimens, $i_{\text {crit }}$ and $i_{\text {pass }}$ shows same tendencies as the specimen A (Electropolish), and those parameters were decreased by more than $70 \%$ by applying a cavitating jet to the backs of the specimens to control the residual stress.

\section{Discussion}

The variation of the current density by the surface finish can be explained by the variation of surface activity. The surface finish affects surface conditions such as dislocation, grain size and residual stress etc. In particular, the residual stress is greatly affected by the condition of surface finish such as heat generated by the finishing process [23] [24]. Figure 11 shows an X-ray diffraction profile of the specimens finished by Electropolish (specimen A), Emery paper \#800 (specimen B), Rubber polisher \#240 (specimen C) and Angle grinder (specimen D). As shown in Figure 11, the surface finish largely affected X-ray diffraction profile. It is well known that the profile includes much information of the metal surface such as surface texture (dislocation structure, microstrain in grain), grain size and residual stress etc. [25] [26]. The variation of current density depending on surface finish as shown in Figure 6 was attributed to those factors. Y. Wang reported that the surface activity has a large effect on the corrosion resistance of material and the reaction of dislocation on the surface affects the surface activity [27]. The variation of the anodic polarization curve due to the surface finish can be caused by the difference of surface activity, including dislocations, grain size and residual stress. In the view point of the grain size 


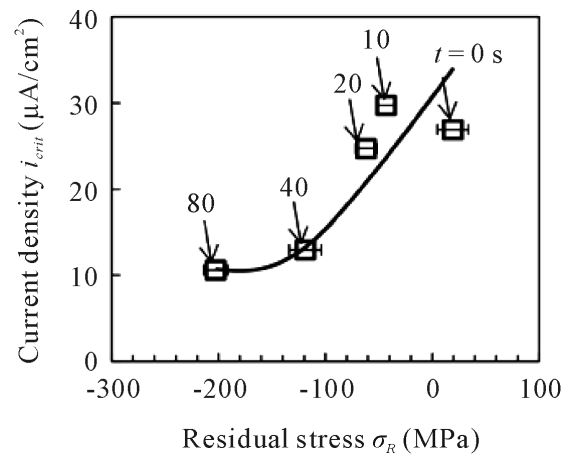

(a)

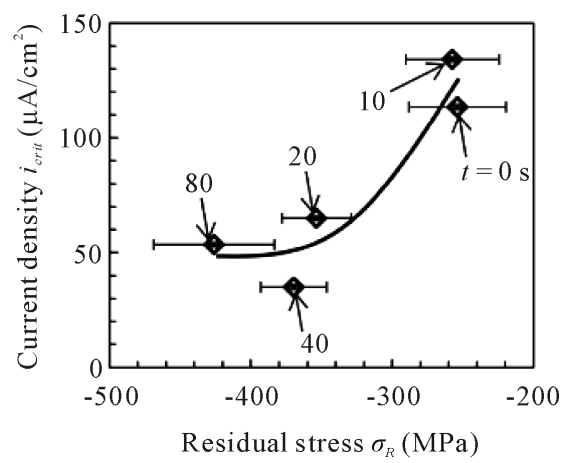

(c)

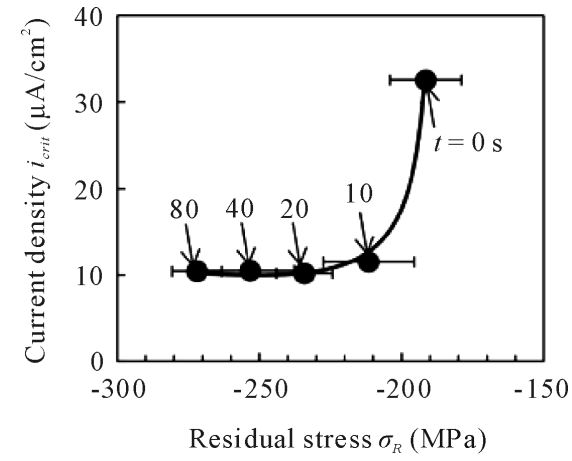

(b)

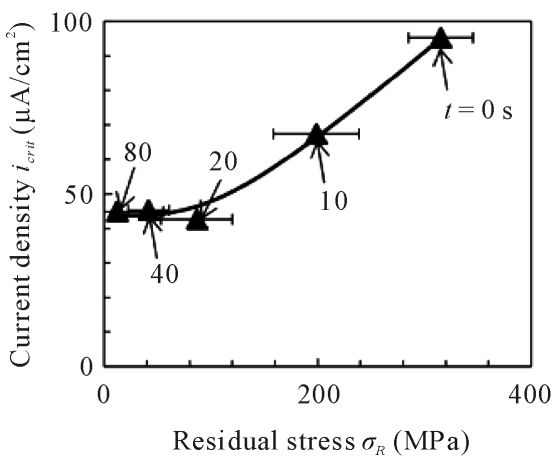

(d)

Figure 9. Critical current density for passivation decreasing with decreasing residual stress.

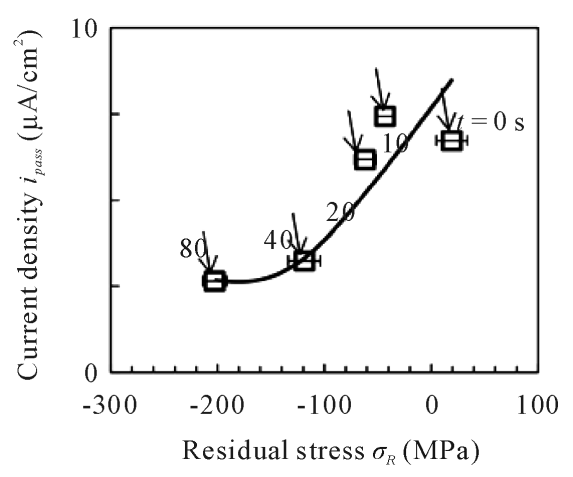

(a)

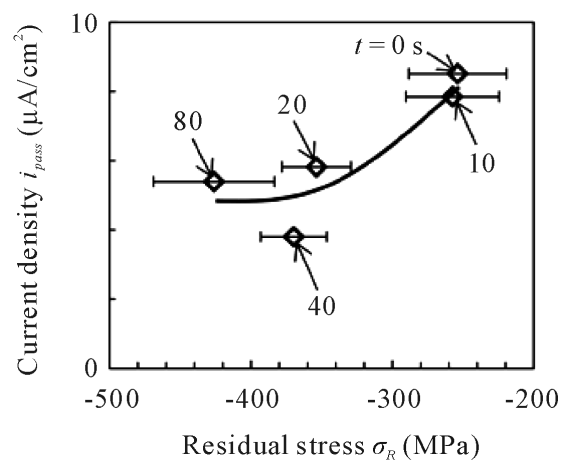

(c)

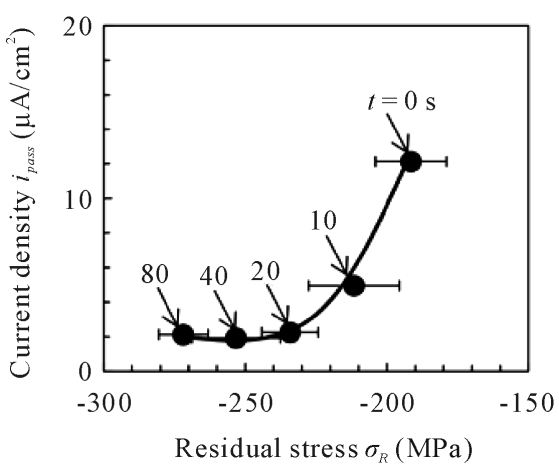

(b)

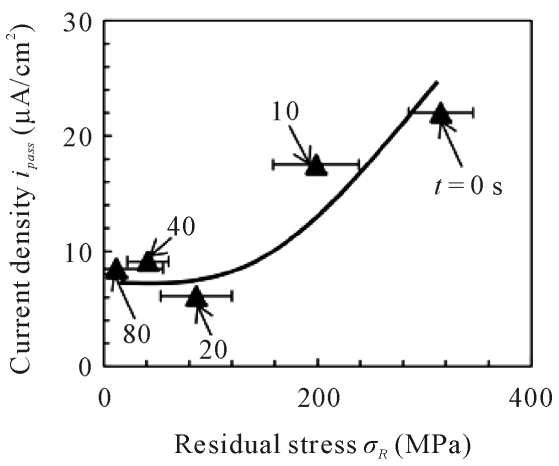

(d)

Figure 10. Passive current density for passivation decreasing with decreasing residual stress. 


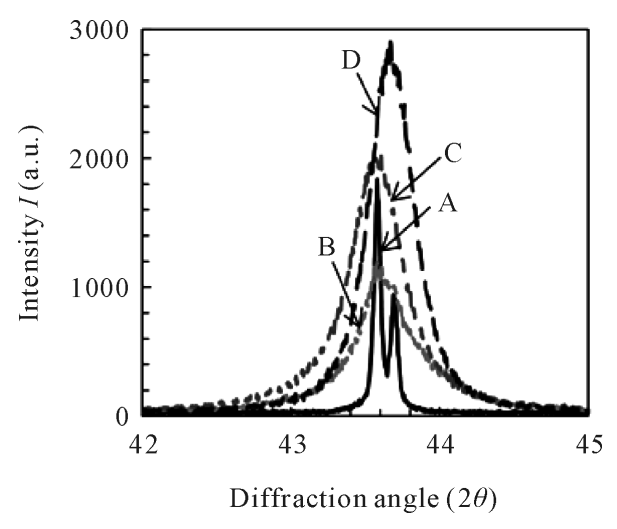

Figure 11. X-ray diffraction profile affected by surface finish.

and metallic structure, the nanosize grains and strain induced martensite formed at the surface by shot-peening and ultrasonically peening methods, and they affected the anodic polarization curve, i.e., current density, of the 304 austenitic stainless steel [14]. Also, the high-density grain boundaries can promote the diffusion of chromium and it may strengthen the passive film [28]. It is quite likely that the variation of the current density depends on the surface texture which was changed by the surface finish.

Since the critical current density and the current density for passivation of all specimens were reduced by the introduction of compressive stress at surface without the variation of the surface texture, it can be considered with the exception of the factors other than the residual stress. The reduction of the current density by the introduction of compressive stress, as shown in Figure 8, Figure 9 and Figure 10, can be considered by the construction and growth of the passive film. The results indicate that the passive film could be constructed and kept by lower current density during the corrosion process compared to that of without the compressive stress. It was reported that the current density of aluminum alloy was reduced by the compressive stress and it can suppress rupture of the passive film contrary to the tensile stress [29]. Although there is a difference the construction behavior of the passive film between the stainless steel and the aluminum alloy, the role of compressive stress might be same as far as an auxiliary role for the construction and maintenance of the passive film goes. In addition, the current density of 316L stainless steel could be reduced by laser-peening and shot peening with introduction of large compressive residual stress, and the compressive residual stress assumes a role of the construction and growth of the passive film in austenitic stainless steel [13]. In viewpoint of an interatomic distance, the compressive residual stress narrows the interatomic distance contrary to the tensile residual stress and the thickening the chromium atoms at surface layer by the compressive residual stress can make it easy to construct, grow and keep the passive film. Further research based on the evaluation of the passive film varying with the residual stress would clarify the effect of residual stress on the corrosion behavior more precisely.

\section{Conclusions}

In this paper, in order to demonstrate the effect of residual stress on the corrosion behavior of austenitic stainless steel, corrosion tests using an electrochemical method were conducted on specimens made of Japanese Industrial Standards SUS316L. The specimens were treated by several different surface finishes, and in order to exclude the effect of factors other than residual stress, such as surface texture, micro-strain and grain size, which can affect the corrosion behavior and thereby the generation of a passivation layer, the residual stress in each specimen was varied by generating curvature in it by applying a cavitating jet to the back of it. The conclusions obtained in the present study are summarized as follows.

1) Surface finish caused the residual stress at surface and the anodic polarization curve was affected largely by the surface finish. In addition, the current density such as the critical current density for passivation and the passive current density was decreased rapidly with increasing the compressive stress. Depending on the type of surface finish, those current densities were decreased by more than $70 \%$ by introduction of compressive stress.

2) The introduction of compressive residual stress makes producing the passivation film easier regardless of the surface condition varied by surface finish since the passive film can be produced and maintained at low cur- 
rent density. This might be the reason why the reduction of interatomic spacing due to the compressive stress at surface can facilitate the growth and maintenance of the passivation film. The compressive residual stress enhances not only the mechanical properties but also the corrosion resistance.

\section{Acknowledgements}

This work was partly supported by JSPS KAKENHI Grant number 24360040.

\section{References}

[1] Boven, G.V., Chen, W. and Rogge, R. (2006) The Role of Residual Stress in Neutral pH Stress Corrosion Cracking of Pipeline Steels. Part I: Pitting and Cracking Occurrence. Acta Materialia, 55, $29-42$.

[2] Mochizuki, M. (2007) Control of Welding Residual Stress for Ensuring Integrity against Fatigue and Stress-Corrosion Cracking. Nuclear Engineering and Design, 237, 107-123. http://dx.doi.org/10.1016/j.nucengdes.2006.05.006

[3] Soyama, H., Saito, K. and Saka, M. (2002) Improvement of Fatigue Strength of Aluminum Alloy by Cavitation ShotLess Peening. Journal of Engineering Materials and Technology, Transactions of the ASME, 124, 135-139. http://dx.doi.org/10.1115/1.1447926

[4] Soyama, H., Shimizu, M., Hattori, Y. and Nagasawa, Y. (2008) Improving the Fatigue Strength of the Elements of a Steel Belt for CVT by Cavitation Shotless Peening. Journal of Materials Science, 43, 5028-5030. http://dx.doi.org/10.1007/s10853-008-2743-6

[5] Kobayashi, M., Matsui, T. and Murakami, Y. (1998) Mechanism of Creation of Compressive Residual Stress by Shot Peening. International Journal of Fatigue, 20, 351-357. http://dx.doi.org/10.1016/S0142-1123(98)00002-4

[6] Soyama, H., Kikuchi, T., Nishikawa, M. and Takakuwa, O. (2010) Introduction of Compressive Residual Stress into Stainless Steel by Employing a Cavitating Jet in Air. Surface and Coatings Technology, 205, 3167-3174. http://dx.doi.org/10.1016/j.surfcoat.2010.11.031

[7] Sano, Y., Akita, K., Masaki, K., Ochi, Y., Altenberger, I. and Scholtes, B. (2006) Laser Peening without Coating as a Surface Enhancement Technology. Journal of Laser Micro/Nanoengineering, 1, 161-166. http://dx.doi.org/10.2961/jlmn.2006.03.0002

[8] Sedriks, A.J. (1996) Corrosion of Stainless Steels. 2nd Edition, Wiley-Interscience, New York.

[9] Begujm, Z., Poonguzhali, A., Basu, R., Sudha, C., Shaikh, H., Rao, R.V.S., Patil, A. and Dayal, R.K. (2011) Studies of the Tensile and Corrosion Fatigue Behaviour of Austenitic Stainless Steels. Corrosion Science, 53, 1424-1432. http://dx.doi.org/10.1016/j.corsci.2011.01.003

[10] Davoodi, A., Pakshir, M., Babaiee, M. and Ebrahimi, G.R., (2011) A Comparative H2S Corrosion Study of 304L and 316L Stainless Steels in Acidic Media. Corrosion Science, 53, 399-408. http://dx.doi.org/10.1016/j.corsci.2010.09.050

[11] Vignal, V., Zhang, H., Delrue, O., Heintz, O., Popa, I. and Peultier, J. (2011) Influence of Long-Term Ageing in Solution Containing Chloride. Corrosion Science, 53, 894-903. http://dx.doi.org/10.1016/j.corsci.2010.11.011

[12] Garcia, C., Tiedra, M.P., Blanco, Y., Martin, O. and Martin, F. (2008) Intergranular Corrosion of Welded Joints of Austenitic Stainless Steels Studied by Using an Electrochemical Minicell. Corrosion Science, 50, 2390-2397. http://dx.doi.org/10.1016/j.corsci.2008.06.016

[13] Peyre, P., Scherpereel, X., Berthe, L., Carboni, C., Fabbro, R., Beranger, G. and Lemaitre, C. (2000) Surface Modifications Induced in 316L Steel by Laser Peening and Shot Peening. Influence on Pitting Corrosion Resistance. Materials Science and Engineering A, 280, 294-302. http://dx.doi.org/10.1016/S0921-5093(99)00698-X

[14] Lee, H., Kim, D., Jung, J., Pyoun, Y. and Shin, K. (2009) Influence of Peening on the Corrosion Properties of AISI 304 Stainless Steel. Corrosion Science, 51, 2826-2830. http://dx.doi.org/10.1016/j.corsci.2009.08.008

[15] Azer, V., Hashemi, B. and Yazdi, M.R. (2010) The Effect of Shot Peening on Fatigue and Corrosion Behaviour of 316L Stainless Steel in Ringer's Solution. Surface and Coatings Technology, 204, 3546-3551. http://dx.doi.org/10.1016/j.surfcoat.2010.04.015

[16] Bahadur, A., Kumar, B.R. and Chowdhury, S.G. (2004) Evaluation of Changes in X-Ray Elastic Constants and Residual Stress as a Function of Cold Rolling of Austenitic Steels. Materials Science and Technology, 20, 387-392. http://dx.doi.org/10.1179/026708304225012170

[17] Kumar, B.R., Mahato, B. and Singh, R., Kumar, B.R., Mahato, B. and Singh, R. (2007) Influence of Cold-Worked Structure on Electrochemical Properties of Austenitic Stainless Steels. Metallurgical and Materials Transactions A, 38, 2085-2094. http://dx.doi.org/10.1007/s11661-007-9224-4

[18] Peguet, L., Malki, B. and Baroux, B. (2009) Effect of Austenite Stability on the Pitting Corrosion Resistance of Cold Worked Stainless Steels. Corrosion Science, 51, 493-498. http://dx.doi.org/10.1016/j.corsci.2008.12.026 
[19] Ghanem, F., Braham, C., Fitzpatrick, M.E. and Sidhom, H. (2002) Effect of Near-Surface Residual Stress and Micro-Structure Modification from Machining on the Fatigue Endurance of a Tool Steel. Journal of Materials Engineering and Performance, 11, 631-639. http://dx.doi.org/10.1361/105994902770343629

[20] Turnbull, A., Mingard, K., Lord, J.D., Roebuck, B., Tice, D.R., Mottershead, K.J., Fairweather, N.D. and Bradbury, A.K. (2011) Sensitivity of Stress Corrosion Cracking of Stainless Steel to Surface Machining and Grinding Procedure. Corrosion Science, 53, 3398-3415. http://dx.doi.org/10.1016/j.corsci.2011.06.020

[21] Takakuwa, O., Kawaragi, Y. and Soyama, H. (2013) Estimation of the Yield Stress of Stainless Steel from the Vickers Hardness Taking Account of the Residual Stress. Journal of Surface Engineered Materials and Advanced Technology, 3, 262-268. http://dx.doi.org/10.4236/jsemat.2013.34035

[22] Soyama, H. (2011) Enhancing the Aggressive Intensity of a Cavitating Jet by Means of the Nozzle Outlet Geometry. Journal of Fluids Engineering, Transactions of the ASME, 133, Article ID: 101301.

[23] Outeiro, J.C., Pina, J.C., Saoubi, R.M., Pusavec, F. and Jawahir, I.S. (2006) Analysis of Residual Stresses Induced by Dry Turning of Difficult-to-Machine Materials. International Journal of Machine Tools and Manufacture, 46, 17861794. http://dx.doi.org/10.1016/j.ijmachtools.2005.11.013

[24] Lazoglu, I., Ulutan, D., Alaca, B.E., Engin, S. and Kaftanoglu, B. (2008) An Enhanced Analytical Model for Residual Stress Prediction in Machining. Manufacturing Technology, 57, 81-84.

[25] Ungar, T. and Borbely, A. (1996) The Effect of Dislocation Contrast on X-Ray Line Broadening: A New Approach to Line Profile Analysis. Applied Physics Letters, 69, 3173-3175. http://dx.doi.org/10.1063/1.117951

[26] Barabash, R. (2001) X-Ray and Neutron Scattering by Different Dislocation Ensembles. Materials Science and Engineering A, 309-310, 49-54. http://dx.doi.org/10.1016/S0921-5093(00)01663-4

[27] Wang, Y., Zhao, W., Ai, H., Zhou, X. and Zhang, T. (2011) Effects of Strain on the Corrosion Behaviour of X80 Steel. Corrosion Science, 53, 2761-2766. http://dx.doi.org/10.1016/j.corsci.2011.05.011

[28] Wang, X.Y. and Li, D.Y. (2002) Mechanical and Electrochemical Behavior of Nanocrystalline Surface of 304 Stainless Steel. Electrochimica Acta, 47, 3939-3947. http://dx.doi.org/10.1016/S0013-4686(02)00365-1

[29] Liu, X. and Frankel, G.S. (2006) Effects of Compressive Stress on Localized Corrosion in AA2024-T3. Corrosion Science, 48, 3309-3329. http://dx.doi.org/10.1016/j.corsci.2005.12.003 
Scientific Research Publishing (SCIRP) is one of the largest Open Access journal publishers. It is currently publishing more than 200 open access, online, peer-reviewed journals covering a wide range of academic disciplines. SCIRP serves the worldwide academic communities and contributes to the progress and application of science with its publication.

Other selected journals from SCIRP are listed as below. Submit your manuscript to us via either submit@scirp.org or Online Submission Portal.
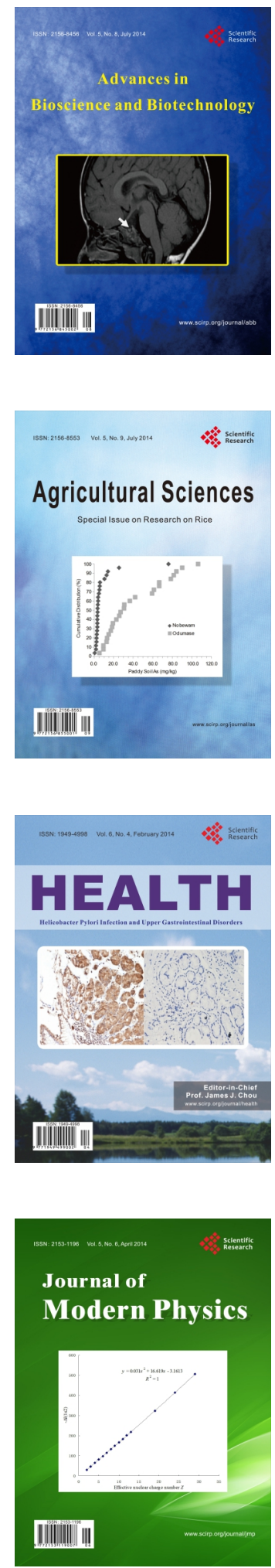
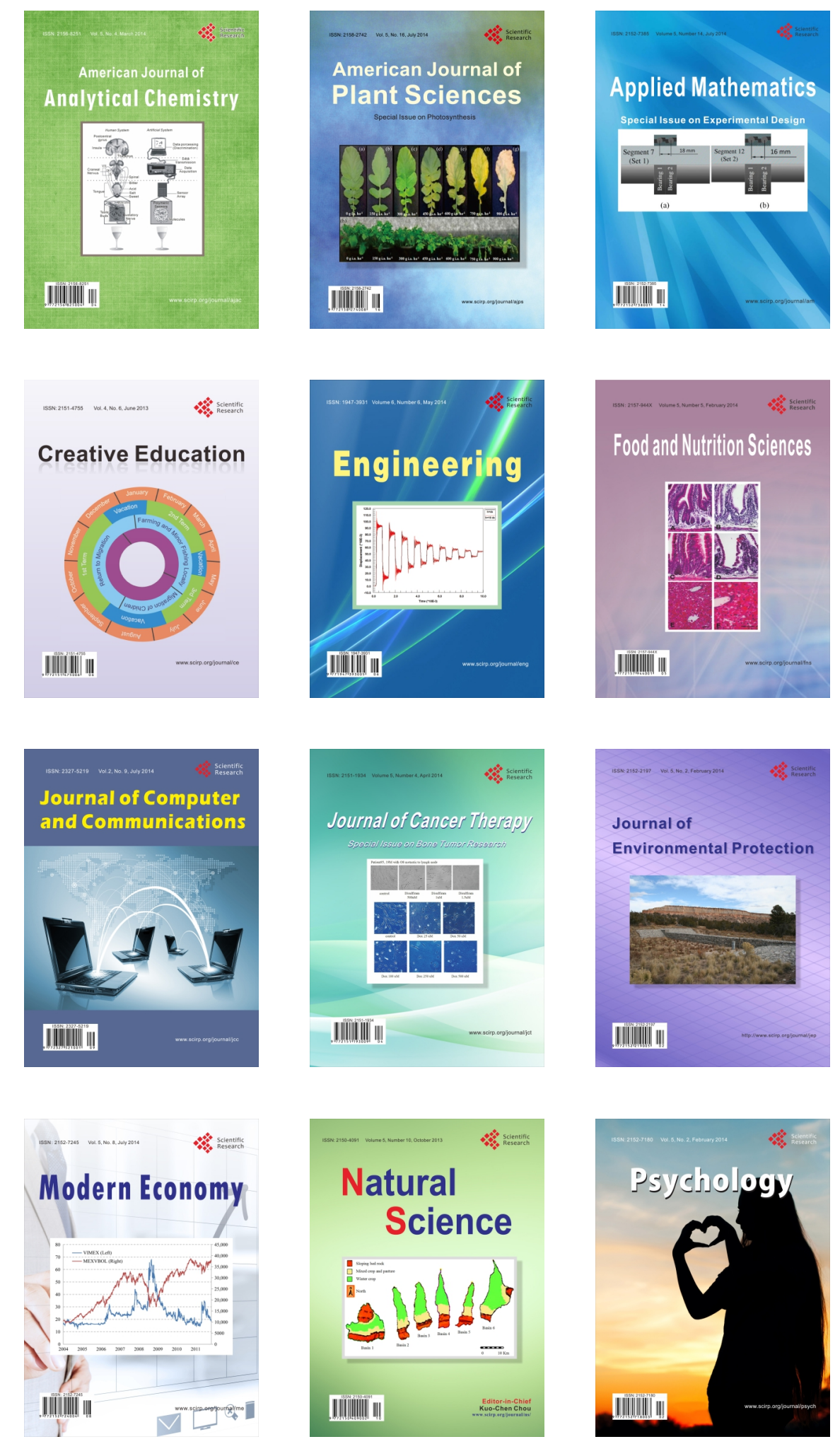